\title{
sciendo
}

\section{WHITE TEA IS MORE EFFECTIVE IN PRESERVATION OF BONE LOSS IN ADULT RATS CO-EXPOSED TO LEAD AND CADMIUM COMPARED TO BLACK, RED OR GREEN TEA*}

\author{
Ewa Tomaszewska ${ }^{1 \bullet}$, Siemowit Muszyński $^{2}$, Piotr Dobrowolski ${ }^{3}$, Anna Winiarska-Mieczan $^{4}$, \\ Małgorzata Kwiecieńn ${ }^{4}$, Agnieszka Tomczyk-Warunek ${ }^{1}$, Marta Ejtel², Izabela Świetlicka², \\ Bożena Gładyszewska²
}

\author{
${ }^{1}$ Department of Animal Physiology, Faculty of Veterinary Medicine, \\ University of Life Sciences in Lublin, Poland \\ ${ }^{2}$ Department of Physics, Faculty of Production Engineering, \\ University of Life Sciences in Lublin, Poland \\ ${ }^{3}$ Department of Comparative Anatomy and Anthropology, \\ Maria Curie-Skłodowska University, Lublin, Poland \\ ${ }^{4}$ Institute of Animal Nutrition and Bromatology, University of Life Sciences in Lublin, Poland \\ •Corresponding author: ewaRST@interia.pl
}

\begin{abstract}
Lead $(\mathrm{Pb})$ and cadmium $(\mathrm{Cd})$ are toxic metals occurring commonly in the human environment that show mutagenic, genotoxic and carcinogenic effects. Dietary components could prevent heavy metals intoxication by reducing their accumulation in the body. The purpose of the study was to check possible protective effect of regular consumption of white, black, red, or green tea on bone metabolism during long-term exposure to $\mathrm{Pb}$ and $\mathrm{Cd}$ in adult rats. The 12 week-long exposure to $\mathrm{Pb}$ and $\mathrm{Cd}(50 \mathrm{mg} \mathrm{Pb}$ and $7 \mathrm{mg} \mathrm{Cd} / \mathrm{kg}$ of the diet) in a rat model was studied. Twelve-week-old adult male Wistar rats were randomly divided into a negative control group ( $\mathrm{Pb}$ and $\mathrm{Cd}$ exposure without tea), a control (without $\mathrm{Pb}$ and $\mathrm{Cd}$ and teas), and groups co-exposed to $\mathrm{Pb}$ and $\mathrm{Cd}$ and supplemented with green, red, black, or white tea (n=12 each group). The experiment lasted for 12 weeks. The coexposure to $\mathrm{Pb}$ and $\mathrm{Cd}$ led to the increase of bone resorption depending on the teatment, which was confirmed by the mechanical testing and histomorphometrical examination of cancellous bone. $\mathrm{Pb}$ and $\mathrm{Cd}$ influenced mechanical strength, reduced the densitometric and geometric parameters and the thickness of growth plate and articular cartilages. Concluding, white tea exerted the best protective effect on bone tissue and hyaline cartilage against heavy metal action.
\end{abstract}

Key words: cadmium, lead, tea, adult rats, femur, geometry, mechanical endurance

Lead $(\mathrm{Pb})$ and cadmium $(\mathrm{Cd})$ are toxic metals widespread in the human environment with a long biological half-life within the organ system (Hogervorst et al.,

\footnotetext{
*Study funded from Statutory Research of Department of Physics, University of Life Sciences in Lublin, no. TKF/DS-1.
} 
2007). Both can accumulate in the human body when taken up from food intake, drinking water, cigarette smoke, or occupational exposure. After absorption from the digestive tract, heavy metals are first transported to the liver, next to kidney, heart or brain, and later to the bone tissue or muscle, giving adverse health effects (WHO, 1992; Chen et al., 2011; Lim et al., 2016). Long-term exposure to Pb and Cd causes a toxic effect, mainly in the liver, and can alter the organization of intestinal mucosa (Tomaszewska et al., $2015 \mathrm{a}, \mathrm{b}$ ). The mechanism of toxicity of these heavy metals is also linked to bone damage through the substitute of divalent calcium due to structural similarities (Tomaszewska et al., 2016, 2017 a).

Tea is one of the most frequently consumed beverages in the world and is classified as a functional food product (Gaur and Agnihori, 2014). Each type of tea has different content of antioxidants, mainly polyphenols, which determine its health properties (Hilal and Engelhardt, 2007; Gaur and Agnihori, 2014). One of the strongest antioxidant naturally occurring in tea is tannic acid, which strongly binds toxic metals (Gülçin et al., 2010; Khalaf et al., 2012). This is particularly important in the case of contamination of the human environment with heavy metals including water or food, that is a global issue (EFSA, $2012 \mathrm{a}, \mathrm{b})$. There are studies reporting reduced risk of hip fractures in habitual tea drinkers (Sheng et al., 2014) or showing that bone mineral density in postmenopausal women who drank tea was higher compared to those who did not (Devine et al., 2007; Lim et al., 2016; Zhang et al., 2017). Despite the fact that different types of tea have been reported to show phytoestrogenic effectiveness, there is a lack of study discussing the influence of different types of tea on the functional adaptation and mineralization of the vertebrate skeleton of adults in the $\mathrm{Cd}$ or $\mathrm{Pb}$ co-exposure, which can contribute to bone loss as osteoporosis by decreasing calcium content in bone.

The lack of knowledge on health-promoting effects of black, green, white or red tea in bone loss in adults co-exposed to heavy metal action motivated us to determine their role in preservation of bone mass in co-exposure to $\mathrm{Pb}$ and $\mathrm{Cd}$ in an adult rats model study.

\section{Material and methods}

The experimental procedures used throughout this study were approved by the Second Local Ethics Committee on Animal Experimentation at the University of Life Sciences in Lublin, Lublin, Poland (1/2011). All experiments complied with the Directive 2010/63/EU of the European Parliament and of the Council of 22 September 2010 on the protection of animals used for scientific purposes.

\section{Animals and basal diet}

Adult (12-week-old) male Wistar rats $(n=72)$ after individual weighing $(345.6 \pm 8.6 \mathrm{~g})$ were placed separately in polypropylene cages (the dimensions of $380 \times 200 \times 590 \mathrm{~mm}$ ) and left for 7 days to acclimate to new laboratory conditions. The rats were held at a temperature of $21 \pm 3^{\circ} \mathrm{C}$, humidity of $55 \pm 5 \%$, and in $12 \mathrm{~h} / 12 \mathrm{~h}$ day/night cycle; had a free access to water. After the acclimatization period, the ani- 
mals were randomly distributed into a control group $(\mathrm{n}=12)$ not co-exposed to $\mathrm{Pb}$, $\mathrm{Cd}$ and teas (the $\mathrm{C}$ group); a negative control group $(\mathrm{n}=12)$ co-exposed to $\mathrm{Pb}$ and $\mathrm{Cd}$ (the $\mathrm{NC}$ group); and 4 groups subjected to $\mathrm{Pb}$ and $\mathrm{Cd}$ co-exposure and tea supplementation: green (the GT group; $n=12$ ), red (the RT group; $n=12$ ), black (the BT group; $n=12$ ), and white tea (the WT group; $n=12$ ). Teas preparation procedure was described in details previously (Tomaszewska et al., 2015 a) Briefly, commercially available tea bags (Lipton, China) weighing approx. $2 \mathrm{~g}$ were brewed at $200 \mathrm{ml}$ of hot $\left(\mathrm{ca} .90^{\circ} \mathrm{C}\right.$ ) distilled water for $5 \mathrm{~min}$. Obtained infusions were divided into $30 \mathrm{ml}$ portions and frozen. Every 2 days, a fresh experimental solution was made, mixing the thawed infusion with distilled water at room temperature. The rats in the $\mathrm{C}$ group were fed ad libitum standard laboratory rodents diet, formulated to meet minimal nutritional requirements specified in AIN-93M (Reeves et al., 1993). The diet contained $160 \mathrm{~g}$ protein, $28 \mathrm{~g}$ fat, $50 \mathrm{~g}$ crude fibre, $70 \mathrm{~g}$ crude ash in $1 \mathrm{~kg}$ of feed, metabolizable energy of $11 \mathrm{MJ} / 1 \mathrm{~kg}$ feed dry mass. The rats co-exposed to $\mathrm{Pb}$ and $\mathrm{Cd}$ were fed the same diet mixed with $50 \mathrm{mg} \mathrm{Pb} \times \mathrm{kg}^{-1}\left(1000 \mathrm{mg} \mathrm{Pb}\right.$ as $\left.\mathrm{Pb}\left(\mathrm{NO}_{3}\right)_{2} / 1 \mathrm{~L} \mathrm{H}_{2} \mathrm{O}\right)$ and $7 \mathrm{mg}$ $\mathrm{Cd} \times \mathrm{kg}^{-1} \mathrm{Cd}\left(1000 \mathrm{mg} \mathrm{Cd}\right.$ as $\mathrm{CdCl}_{2} / 1 \mathrm{~L} \mathrm{H}_{2} \mathrm{O}$ ) of a diet (Merck, Germany). The fodder was ground, mixed with heavy metal solutions and then re-extruded. The concentration of the heavy metals in the feed was calculated to ensure that the daily exposure to $\mathrm{Pb}$ and $\mathrm{Cd}$ did not exceed the environmental exposure for humans (Tomaszewska et al., 2015 a). To calculate the average weekly supply of Pb and $\mathrm{Cd}$ the weekly intake of feed was monitored (Table 1). The possible larger uptake of $\mathrm{Pb}$ and $\mathrm{Cd}$ from feed or tea infusions was not considered.

After 12 weeks, the rats were fasted for 24 hours, weighed and euthanized by $\mathrm{CO}_{2}$ inhalation. Next, blood was immediately sampled directly from the heart of rats into $6 \mathrm{ml}$ vacuum tubes containing lithium heparin.

\section{Bone analysis}

After the removal of soft tissues each femur weight and length were measured, then wrapped in gauze soaked in isotonic $\mathrm{PhS}$ and frozen at $-25^{\circ} \mathrm{C}$ for further analysis.

The following geometric properties were estimated on the basis of horizontal and vertical diameter measurements of the cross-section of bone midshaft: the crosssection area, cortical index and mean relative wall thickness (Tomaszewska et al., 2012 a; Śliwa et al., 2006).

Femoral mechanical strength was determined after 4-hour thawing at room temperature using the three-point bending test on a universal testing machine (Zwick Z010, Zwick/Roell, Ulm, Germany) (Tomaszewska et al., 2017 b). The bone, placed on the supports set at $40 \%$ of the bone length, was loaded at a constant speed of $10 \mathrm{~mm} / \mathrm{min}$. The elastic strength was determined as maximal force causing elastic deformation of bone and the ultimate strength as the force causing bone fracture (Muszyński et al., 2017; Śliwa et al., 2005).

After the mechanical testing, bone samples (approx. $3 \mathrm{~g}$ ) were ashed in a muffle furnace at $450^{\circ} \mathrm{C}$. The ash was dissolved in $10 \mathrm{ml}$ of $1 \mathrm{~mol} \times \mathrm{L}^{-1} \mathrm{HNO}_{3}$ (Poch S.A., Poland). The content of $\mathrm{Pb}$ and $\mathrm{Cd}$ was determined with atomic absorbance spectrometer (SpectrAA 880, Varian, Santa Clara, CA, USA). The measurements were verified by the use of certified reference material (bovine liver) in blank determination. 


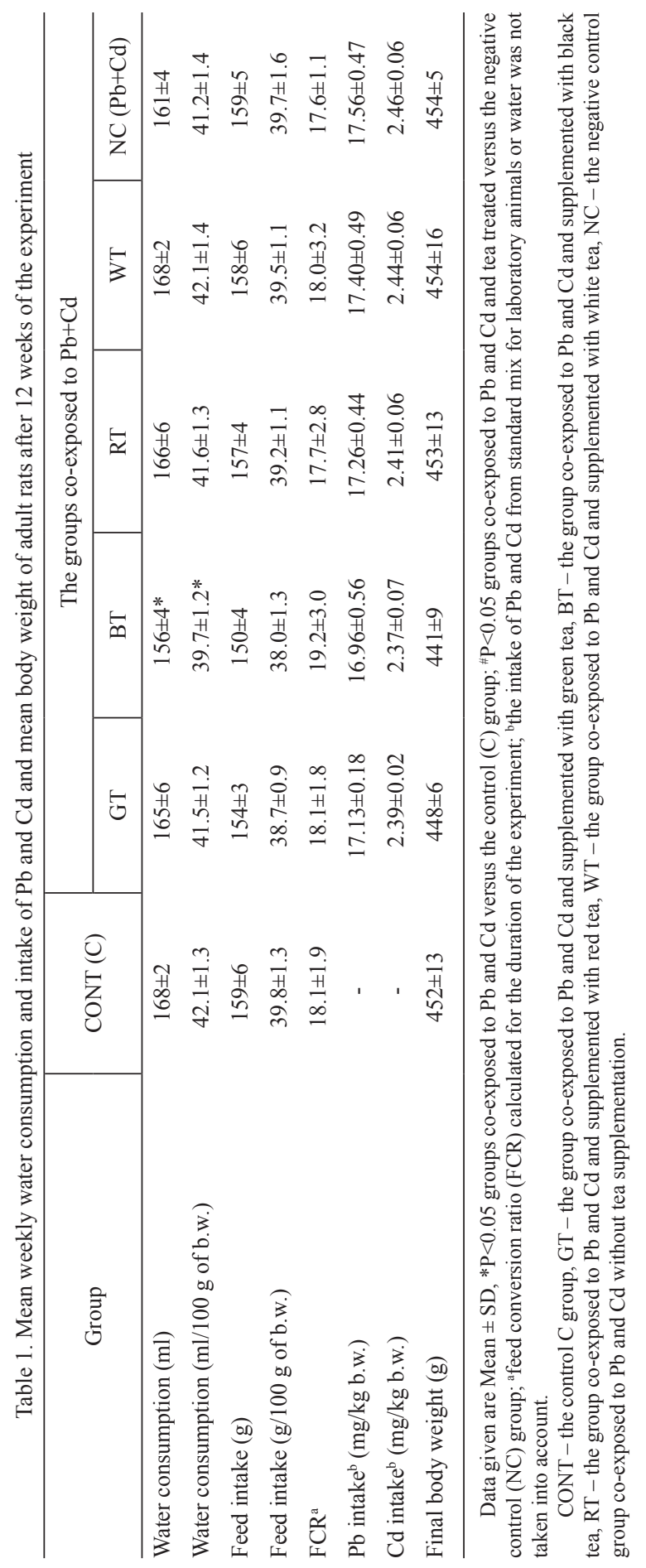


From the middle of the lateral femoral condyle (containing epiphysis and metaphysis) 5-mm thick, cylindrical sample of bone and cartilage was taken from the joint. Sagittal sections (4- $\mu$ m thick slices) were cut perpendicularly to the articular surface and subjected to histology and microscopy procedures (Śliwa, 2010). Goldner's trichrome staining was used to assess the morphology of the growth plate and articular cartilages (Suvara et al., 2013; Lattouf et al., 2015; Dobrowolski et al., 2016). Bright-field images were collected and analyzed using a microscope (Olympus, Tokyo, Japan) and the Olympus cellSens graphical analysis software (Olympus, Tokyo, Japan) (Tomaszewska et al., 2012 b). The thickness of four zones of the growth plate cartilage (reserve (I), proliferation (II), hypertrophy (III) and ossification (IV)) was measured at four sites as well as the thickness of three zones of the articular cartilage: horizontal (superficial, I), transitional (II) and radial (III) as described previously (Tomaszewska et al., 2013). The relative bone volume (BV/ $\mathrm{TV}$ ) was assessed using the pixel count. Trabecular thickness (Tb.Th) and trabecular separation ( $\mathrm{Tb} . \mathrm{Sp}$; defined as the distance between the edges of adjacent trabeculae) and the number of trabeculae were calculated in epiphysis and metaphysis. Staining with safranin $\mathrm{O}$ was applied to assess the Mankin's histological-histochemical grading system and to estimate the content of proteoglycans in articular cartilage (Tomaszewska et al., 2017 a).

\section{Blood plasma biochemical analyses}

The plasma $\mathrm{Pb}$ and $\mathrm{Cd}$ concentrations were determined using the atomic absorbance spectrometry method (SpectrAA 880, Varian, Santa Clara, CA, USA) (Tomaszewska et al., 2016). The plasma was diluted with deionized water (Hydrolab, Gdańsk, Poland) at a ratio of 1:10.

\section{Statistical analysis}

Data are presented as means \pm standard deviation (SD). Differences between means were tested with one-way analysis of variance (one-way ANOVA). The Dunnett's post hoc test was used to compare the groups co-exposed to $\mathrm{Pb}$ and $\mathrm{Cd}$ with or without tea supplementation to the control (the $\mathrm{C}$ group). Planned comparisons were used to compare groups co-exposed to $\mathrm{Pb}$ and $\mathrm{Cd}$ and different tea types with animals co-exposed only to $\mathrm{Pb}$ and $\mathrm{Cd}$ (the $\mathrm{NC}$ group). Normal distribution of data was tested using the Shapiro-Wilk test, equality of variance was examined with the Brown-Forsythe test. When there was no normal distribution and/or unequal variance of data, the Kruskal-Wallis analysis of variance was applied. For all analyses, $\mathrm{P}<0.05$ was considered statistically significant. Data were analyzed using Statistica 12.0 software (StatSoft, Inc., Tulsa, OK, USA).

\section{Results}

There was no effect of heavy metals on the feed intake (total and calculated per $100 \mathrm{~g}$ of body weight) or final body weight, irrespective of the tea treatment com- 
pared to control and negative control groups (Table 1). Also the feed conversion ratio (FCR) calculated for the duration of the experiment was similar in all groups. The $\mathrm{Pb}$ and $\mathrm{Cd}$ intake calculated per body weight was similar in all the groups co-exposed to $\mathrm{Pb}$ and $\mathrm{Cd}$. However, weekly water consumption, total and calculated per $100 \mathrm{~g}$ of body weight, was significantly reduced in rats that drank black tea compared to the $\mathrm{C}$ group.

All rats co-exposed to heavy metals had enhanced blood $\mathrm{Pb}$ and $\mathrm{Cd}$ concentrations compared to the non-exposed $\mathrm{C}$ group (Figure 1). However, the rats drinking tea irrespective of its type had significantly decreased blood $\mathrm{Pb}$ and $\mathrm{Cd}$ concentrations compared to the $\mathrm{NC}$ group, where the concentration of $\mathrm{Pb}$ and $\mathrm{Cd}$ was the highest among co-exposed groups. Irrespective of the tea administration, all rats coexposed to $\mathrm{Pb}$ and $\mathrm{Cd}$ had elevated $\mathrm{Pb}$ and $\mathrm{Cd}$ levels and decreased $\mathrm{Ca}$ content in bone compared to the $\mathrm{C}$ control group (Figure 2). However, rats drinking green, black and white tea had higher $\mathrm{Ca}$ content in bone compared to the rats co-exposed and not drinking tea (the NC group). Moreover, the content of both heavy metals was decreased in bones obtained from rats drinking tea irrespective of its type compared to rats from the NC group (Figure 2).
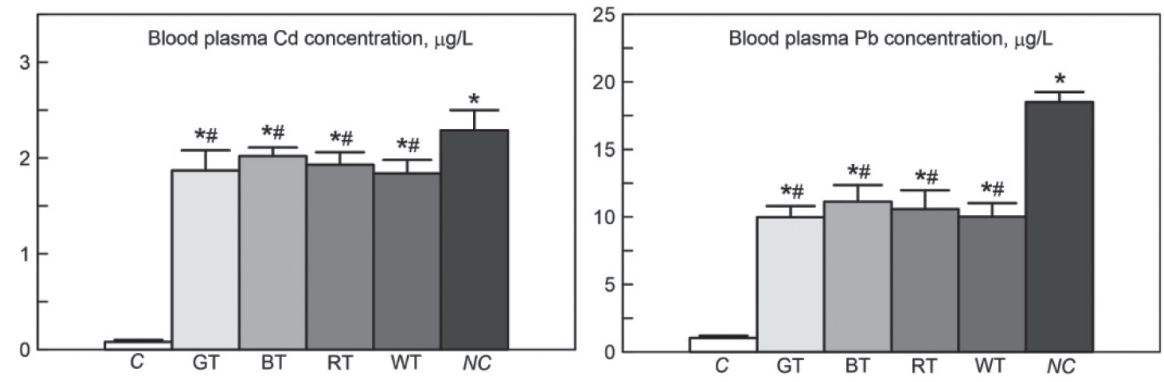

Data given are Mean $\pm \mathrm{SD} ; * \mathrm{P}<0.05$ groups co-exposed to $\mathrm{Pb}$ and $\mathrm{Cd}$ versus the control $(\mathrm{C})$ group; ${ }^{*} \mathrm{P}<0.05$ groups co-exposed to $\mathrm{Pb}$ and $\mathrm{Cd}$ and tea treated versus the negative control (NC) group.

Figure 1. The concentration of cadmium $(\mathrm{Cd})$ and lead $(\mathrm{Pb})$ in blood plasma of adult rats co-exposed to $\mathrm{Pb}$ and $\mathrm{Cd}$ and supplemented with different types of teas for 12 weeks

Heavy metals co-exposure significantly reduced bone weight in the NC group. Moreover, increased bone weight was observed in all groups supplemented with teas, compared both to the $\mathrm{C}$ and $\mathrm{NC}$ groups (Table 2). Bone length was decreased in the $\mathrm{NC}$ group compared to other heavy metals co-exposed groups. The NC group was characterized by the lowest values of parameters describing the mechanical strength of the bone. The tea inclusion resulted in the increase of ultimate strength in all teasupplemented groups when compared to the NC group. Similarly, the elastic strength was higher in tea-supplemented groups, except the GT group (Table 2). The cross section area was reduced in the BT, GT and WT groups compared to the C group, while in the RT group was increased compared to NC group. The reduction of the mean relative wall thickness was noted in the BT and GT groups, while its increase was observed in the RT group. The reduction of the mean relative wall thickness also was observed in the GT, BT and WT groups compared to the NC group. In the BT 
and $\mathrm{NC}$ groups cortical index was reduced compared to the $\mathrm{C}$ group, similarly its values were reduced in the GT, BY and WT groups compared to the NC group (Table 2).
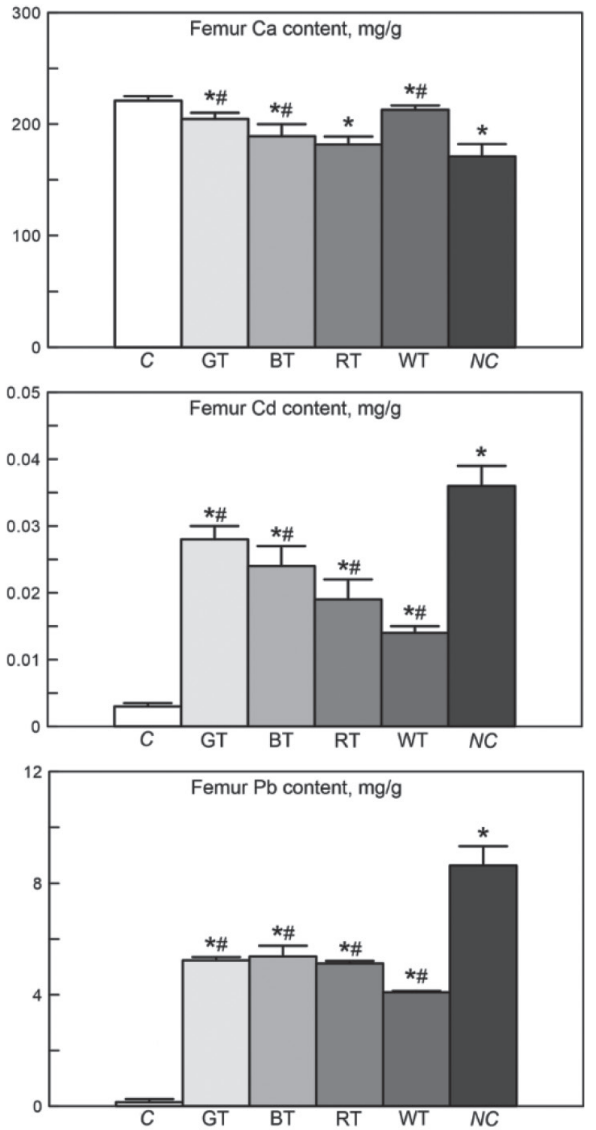

Data given are Mean $\pm \mathrm{SD} ; * \mathrm{P}<0.05$ groups co-exposed to $\mathrm{Pb}$ and $\mathrm{Cd}$ versus the control (C) group; ${ }^{\#} \mathrm{P}<0.05$ groups co-exposed to $\mathrm{Pb}$ and $\mathrm{Cd}$ and tea treated versus the negative control (NC) group.

Figure 2. The bone content of calcium $(\mathrm{Ca})$, cadmium $(\mathrm{Cd})$ and lead $(\mathrm{Pb})$ in adult rats co-exposed to $\mathrm{Pb}$ and $\mathrm{Cd}$ and supplemented with different types of teas for 12 weeks

The BV/TV in femur epiphysis trabecular bone was reduced in all groups coexposed to heavy metals when compared to the $\mathrm{C}$ group, however, in the RT and WT groups BV/TV was higher compared to the NC group (Table 3). The Tb.Th mean was reduced in the GT group compared to $\mathrm{C}$ group, additionally the decrease in the WT group was noted compared to the NC group. The increase was observed in the BT group compared to $\mathrm{C}$ and NC groups. The Tb.Sp max was reduced in femoral epiphysis in RT and WT groups compared to C and NC groups. The Tb.Sp mean in the epiphysis irrespective of the tea administration decreased compared to the $\mathrm{C}$ and NC group (Table 3). Trabeculae number decreased in all groups co-exposed to heavy metals irrespective of tea compared to the $\mathrm{C}$ group, however comparing to the $\mathrm{NC}$ group the increase was noted (Table 3 ). 


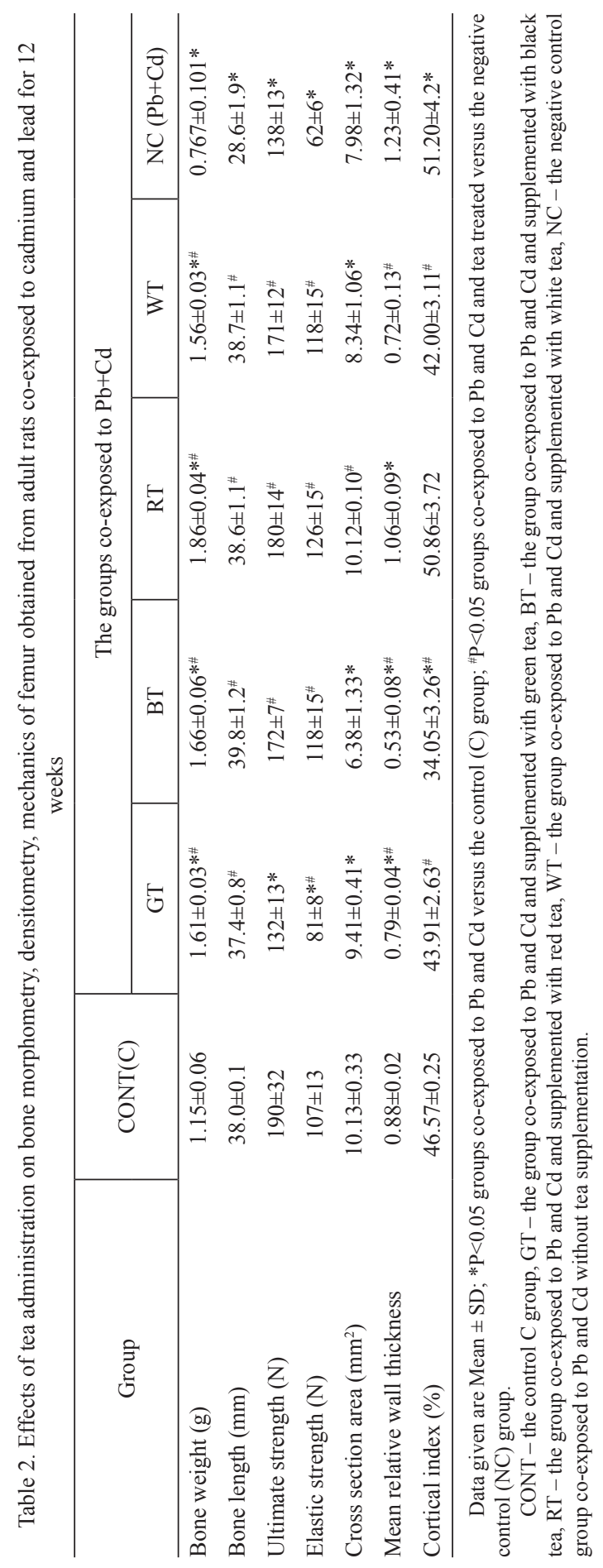




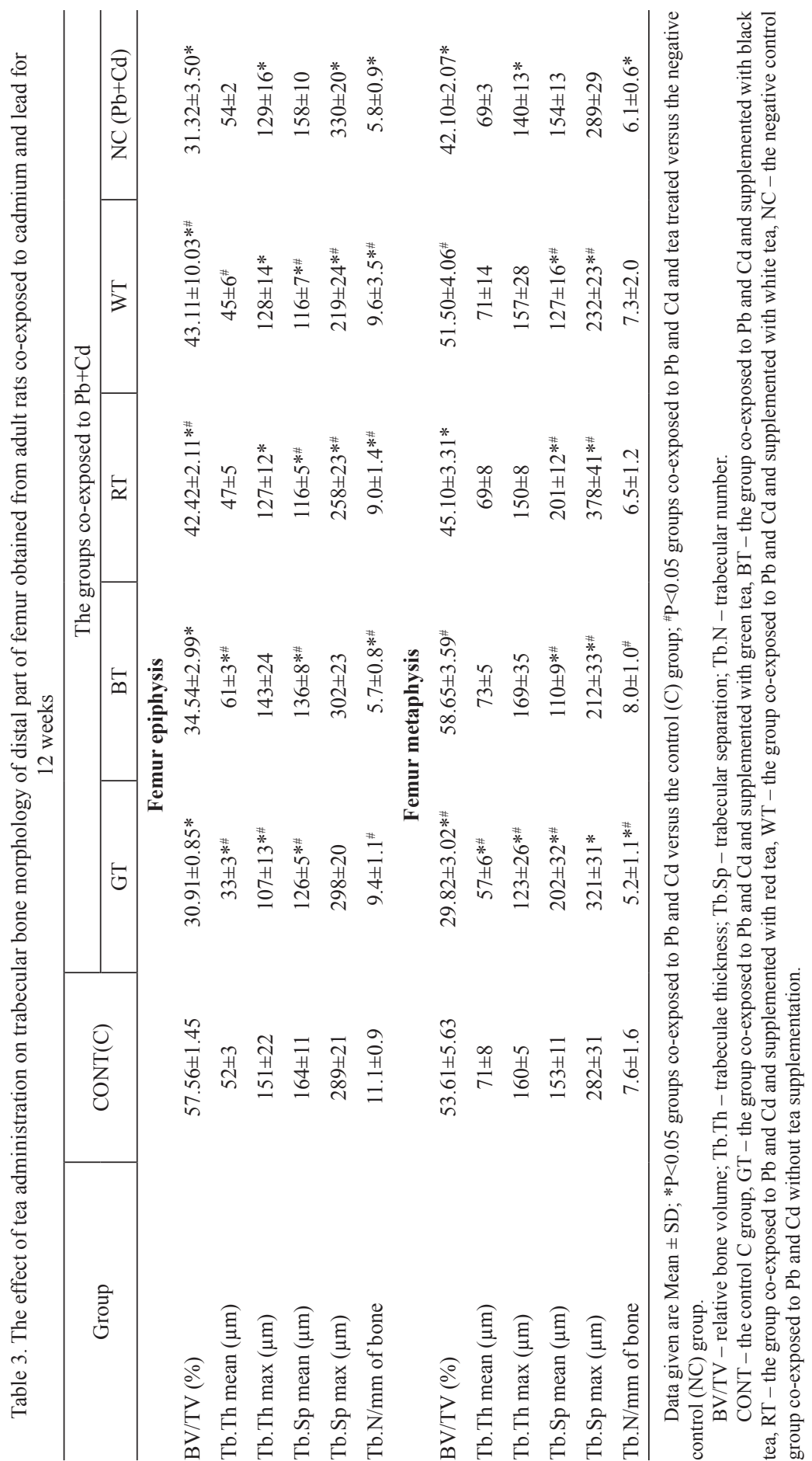



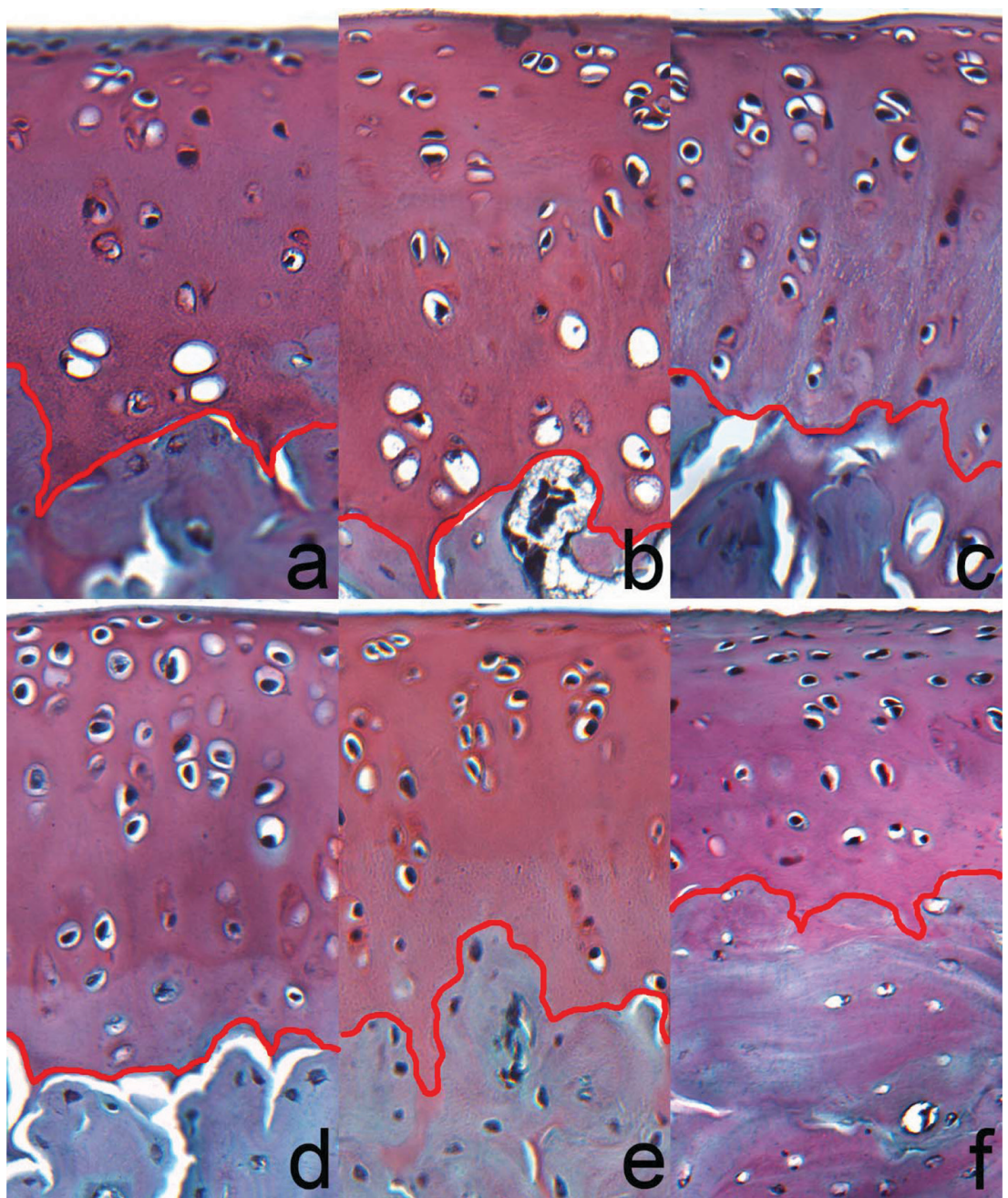

$\mathrm{a}$ - the control $\mathrm{C}$ group, $\mathrm{b}$ - the GT group co-exposed to $\mathrm{Pb}$ and $\mathrm{Cd}$ and supplemented with green tea, $\mathrm{c}$ - the $\mathrm{BT}$ group co-exposed to $\mathrm{Pb}$ and $\mathrm{Cd}$ and supplemented with black tea, $\mathrm{d}$ - the $\mathrm{RT}$ group co-exposed to $\mathrm{Pb}$ and $\mathrm{Cd}$ and supplemented with red tea, $\mathrm{e}$ - the WT group co-exposed to $\mathrm{Pb}$ and $\mathrm{Cd}$ and supplemented with white tea, $\mathrm{f}$ - the negative control group co-exposed to $\mathrm{Pb}$ and $\mathrm{Cd}$ without tea supplementation.

Red lines indicate the bottom border of articular cartilage whereas white arrow indicated its thickness. Proteoglycan staining with SO showed lower proteoglycan content (displaying weaker staining) in the cartilage from the BT, RT, WT and NC groups, while rats from the control and GT groups demonstrated moderate to very strong staining linked with higher content of proteoglycans. The concentration of proteoglycans in all the groups, irrespective of treatment, exhibited a gradual and irregular loss of SO staining. In turn, in the control rats (as a control group), there was no evident gradient in safranin $\mathrm{O}$ staining, and their articular cartilages had strong intensive red staining, compared to the other groups treated with heavy metals. Magnification x200.

Figure 3. Representative images of safranin $\mathrm{O}$ (SO) staining carried out on formaldehyde-fixed sections from the femoral articular cartilage of adult co-exposed to $\mathrm{Pb}$ and $\mathrm{Cd}$ for 12 weeks 


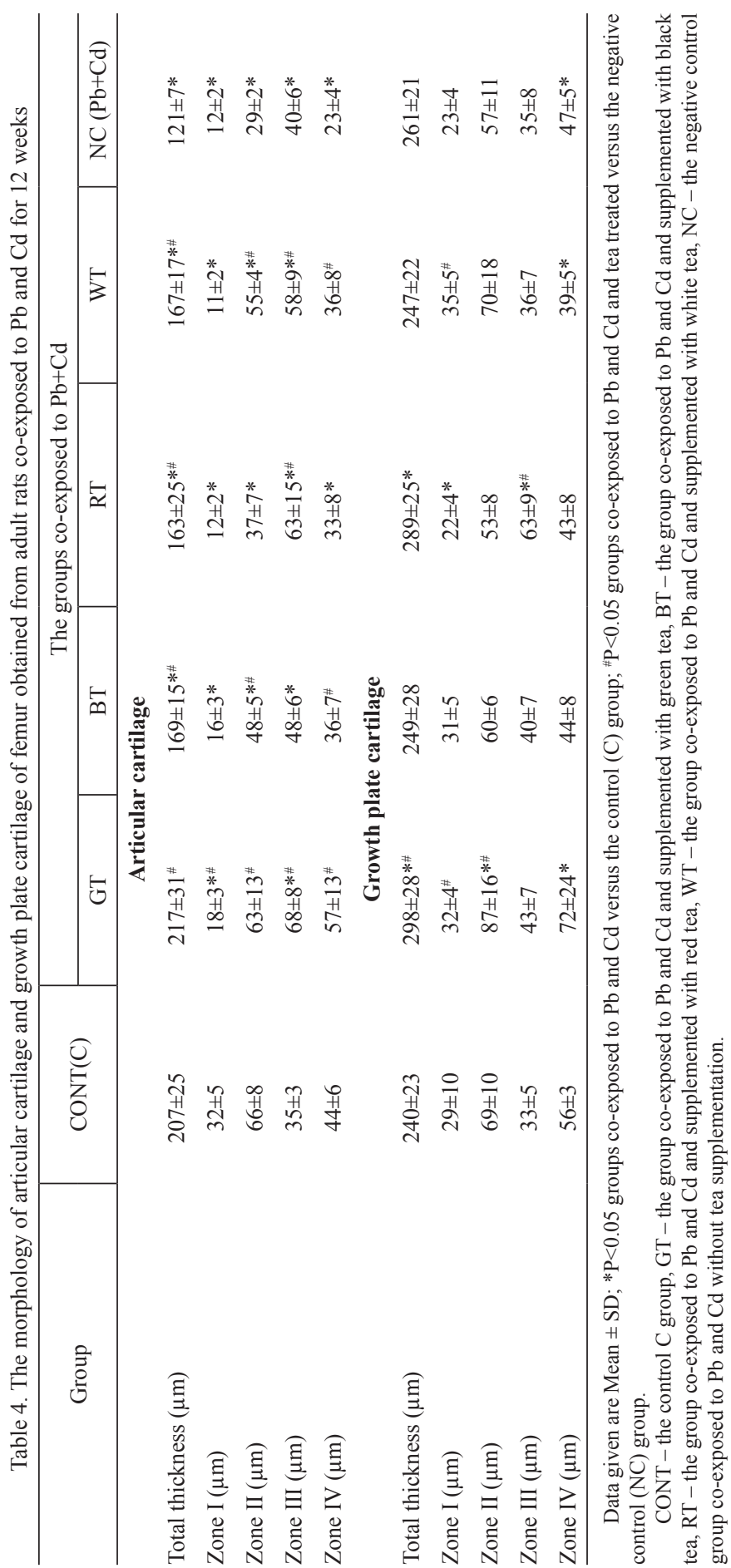


The BV/TV in metaphyseal trabecular bone decreased in the RT, GT and NC groups compared to the $\mathrm{C}$ group. This decrease was also observed in the GT group compared to the NC group, while the increase was noted in the BT and WT groups compared to the NC group (Table 3). Both Tb.Th mean and Tb.Th max in the femoral metaphysis decreased in the GT group compared to the $\mathrm{C}$ and $\mathrm{NC}$ group. The Tb.Th max also decreased in the NC group compared to the $\mathrm{C}$ group. Mean and maximal trabecular space increased in the RT and GT groups and decreased in the WT and BT groups compared to the C group. The Tb.Sp mean increased in the GT and RT groups and decreased in the BT and WT groups compared to the NC group. The Tb.Sp max increased in the RT group and decreased in the BT and WT groups compared to the NC group. The number of trabeculae in metaphysis decreased only in the $\mathrm{NC}$ and GT groups compared to the $\mathrm{C}$ group, while increased in the BT group compared to the NC group. The decrease of trabeculae number was also observed in the GT group compared to the NC group (Table 3).

The co-exposure to $\mathrm{Pb}$ and $\mathrm{Cd}$ decreased the total thickness of articular cartilage in the BT, RT, WT and NC groups compared to the C group (Figure 3, Table 4). The reduction of zone I was noted in all groups co-exposed to heavy metals compared to the $\mathrm{C}$ group, and the increase was observed in the GT group compared to the NC group. The thickness of zone II decreased in the BT, RT, WT and NC groups compared to the $\mathrm{C}$ group, while the increase was observed in the GT, BT and WT groups compared to the NC group. The thickness of zone III increased in all groups co-exposed to PB and Cd, and in the GT, RT and WT groups compared to the NC group. Zone IV became narrower in the RT and NC group compared to the $\mathrm{C}$ group, while became wider in the GT, BT, WT groups compared to the NC group (Table 4).

The total thickness of growth plate cartilage increased in the GT and RT groups compared to the $\mathrm{C}$ group, and this increase was observed in the GT group compared to the NC group. The thickness of zone I decreased in the WT group compared to the $\mathrm{C}$ group, and the increase in the GT and WT groups was observed compared to the $\mathrm{NC}$ group. Zone II in the GT and zone III in the RT group became wider compared to $\mathrm{C}$ and NC groups. The thickness of zone IV increased in GT group, while in the WT and $\mathrm{NC}$ groups decreased compared to the $\mathrm{C}$ group.

Proteoglycan staining with safranin $\mathrm{O}$ showed lower content of proteoglycan (showing weaker staining pattern) in the cartilage from the BT, RT, WT and NC groups, while rats from the control and GT groups demonstrated moderate to very strong staining pattern resulted from higher content of proteoglycans (Figure 3).

According to Mankin's semiquantitative score system, the articular cartilages obtained from rats from the BT, RT, WT and NC groups were characterized by surface irregularity and loss of safranin $\mathrm{O}$ staining, however without structural changes, which gave a score of 3, compared to 0 in the control and GT groups (Figure 3).

\section{Discussion}

The toxicity of $\mathrm{Pb}$ and $\mathrm{Cd}$ is well documented, however the mechanism of their toxic action is not fully known. They cause bone loss (osteomalacia or osteoporo- 
sis) associated with the increased risk of bone fracture (Cretacci and Parsons, 2010; James and Meliker, 2013; Pemmer et al., 2013; Duranova et al., 2014; Tomaszewska et al., 2017 a). Cadmium negatively influences calcium metabolism through calcitotropic hormones, stimulates the proliferation and activity of osteoclasts, reduces osteoblasts and alkaline phosphatase activities leading to decreased mineralization process, simultaneously affects bone collagen synthesis and proteoglycans and glycosaminoglycans content. Moreover, symptoms of Cd toxicity appearing soon after the exposure can persist even when the exposure is stopped (Dermience et al., 2015). Lead also decreases bone mineral density by the inhibition of mineralization and bone turnover. It causes growth retardation through the reduction of endochondral ossification through hormonal-induced cell responses involving vitamin D and insulin like growth factor, and protein synthesis such as osteocalcin, osteopontin, sclerostin and collagen (Chen et al., 2011). Both heavy metals decrease the synthesis of proteoglycans, proteins which in articular cartilage help to form stable matrix capable of withstanding high compressive forces without changing the shape of articular cartilage (Quinn and Morel, 2007; Tomaszewska et al., 2017 a). Moreover, Pb can substitute calcium in hydroxyapatite crystals (Dermience et al., 2015). Finally, Cd or $\mathrm{Pb}$ exposure leads to microarchitectural deterioration of bone tissue and fractures associated with chronic pain, height loss, disability, and reduced quality of life and even with mortality in senior adults (Brzóska, 2012).

Despite numerous studies concerning heavy metals, there is little information about the factors which would be able to prevent or mitigate their action. However, in recent years there has been growing interest in researches concerning different factors, both inorganic and organic, which could limit the action of heavy metals on bone homeostasis (Brzóska et al., 2007). Moreover, there is a study conducted on adolescent rats with different types of teas, but obtained results do not indicate which tea has the best protective effects on bone and hyaline cartilage against heavy metal action (Tomaszewska et al., 2016). Therefore, the study of possible protective effect of different types of tea on bone tissue in adults co-exposed to $\mathrm{Pb}$ and $\mathrm{Cd}$ is crucial for nutritional evaluation, especially as doses of heavy metals examined in this study were comparable to those encountered in either environmental or occupational exposures of humans.

Our study showed that chronic co-exposure to $\mathrm{Pb}$ and $\mathrm{Cd}$ did not influence either final body weight (despite lower water consumption in rats drank black tea) or feed intake, irrespective of the treatment. But the bone length and weight are reduced in the case of co-exposure to $\mathrm{Pb}$ and $\mathrm{Cd}$ without the tea supplementation. The geometrical analysis indicated that the bone shape was changed, which could affect mechanical strength. Obtained results also indicated that heavy metals decreased the bone $\mathrm{Ca}$ content, regardless of tea supplementation. This result was consistent with previous study, where adolescent rats tea-supplemented and co-exposed to $\mathrm{Pb}$ and $\mathrm{Cd}$ at the same concentration and duration of exposure have reduced mechanical strength and lowered bone Ca content (Tomaszewska et al., 2016). Additionally, our rats drinking green tea had the lowest concentration of $\mathrm{Pb}$ and $\mathrm{Cd}$ in blood plasma and their highest concentration in bone. On the other hand, histomorphometric analysis of femoral trabeculae in our adult rats drinking green tea showed significant osteoporotic pro- 
cess in cancellous bone, the loss of trabeculae number in metaphysis. On the other hand, this type of tea also showed protective effect to compact bone tissue (midshaft), as it was revealed by the mechanical testing. Further, our rats drinking white tea had the lowest concentration of heavy metals in blood plasma and bone tissue. Histomorphometric analysis of femoral trabeculae also proved the smallest changes in cancellous bone in rats drinking white tea. It is in contrast with previous study performed on adolescent rats, where a strong negative impact on the bone is evident despite drinking white tea (Tomaszewska et al., 2016). Our adult rats drinking red or black teas had similar concentration of heavy metals in blood plasma as other groups co-exposed to $\mathrm{Pb}$ and $\mathrm{Cd}$. However, the bone tissue, the higher concentration of $\mathrm{Pb}$ and Cd was in the BT group, where significant reduction of geometry was observed. It however did not influence the bone mechanical strength, probably because there was a lack of any noticeable symptoms of osteoporosis.

The co-exposure to $\mathrm{Pb}$ and $\mathrm{Cd}$ of adult rats negatively influenced bone metabolism by altering the process of bone remodeling, leading to reduced mechanical strength depending on the type of tea treatment.

Alterations in the microarchitecture of cancellous bone could be caused by the changes in the growth plate after $\mathrm{Pb}$ and $\mathrm{Cd}$ co-exposure. Present study demonstrated the protective effect of green or red tea supplementation on the growth plate cartilage in rats co-exposed to heavy metals. Other observed alterations in the growth plate could counterbalance some negative effects of heavy metals action, similarly to these presented in earlier studies (Tomaszewska et al., 2016, 2017 a).

In addition, the $\mathrm{Pb}$ and $\mathrm{Cd}$ exposure led to narrowed articular cartilage in adult rats, that could alter the distribution of the load in the joint with subsequent functional consequences like the acceleration of the degradation of articular cartilage and difficulties in movement. This observation, being consistent with one obtained in adolescent rats (Tomaszewska et al., 2016), indicated that heavy metals cause the narrowing of the articular cartilage irrespective of the age. Moreover, lowered content of proteoglycans, especially in all the groups co-exposed to $\mathrm{Pb}$ and $\mathrm{Cd}$ irrespective of tea supplementation (Figure 3), plays a significant role in destabilization of collagen network in articular cartilage and could intensify degradation of articular cartilage (Quinn and Morel, 2007).

We were unable to find any information concerning the effect of tea extracts on bone metabolism of adults co-exposed to heavy metals. Similarly, no studies conducted so far provide a morphological analysis of the hyaline cartilages or trabecular bone of adult rats or other animal supplemented with different teas during co-exposure to $\mathrm{Pb}$ and $\mathrm{Cd}$.

Tea shows anti-allergic or anti-cancer action and antimicrobial properties (Maeda-Yamamoto, 2013; Green et al., 2014) and it appears to be an effective chemo-preventive factor against toxic elements as its antioxidant properties are reported to be much stronger than those of vitamins $\mathrm{E}$ or $\mathrm{C}$ (Niedzwiecki et al., 2016). Tea contains large amount of flavonoids and exerts strong estrogen-like activity. Therefore, tea could play a pivotal role in maintaining bone mineral density in older women, who have low concentrations of endogenous estrogens. Flavonoids from green or black tea can be associated with an increase of bone mineral density via a potent stimula- 
tory effect on osteoblast function (Devine et al., 2007; Shen et al., 2011, 2013). An epidemiological study with habitual tea-drinking postmenopausal women shows that the bone mineral density was higher in tea-drinking individuals than in those who did not consume tea (Devine et al., 2007; Zhang et al., 2017). Additionally, other studies prove that this protective effect of tea relates to the content of tannic acid (Tomaszewska et al., 2016). The content of polyphenol in green or white teas is higher than that in red or black teas (Hilal and Engelhardt, 2007; Brzóska, 2012; Tomaszewska et al., 2017 a).

The present rat model study was conducted to assess whether a regular consumption of different types of tea could exert any protective effect on bone tissue metabolism in adult rats chronically co-exposed to $\mathrm{Pb}$ and $\mathrm{Cd}$. Tea supplementation contributed to the reduction of some of the negative effects of the heavy metals, but this action was varied and dependent on the type of tea. It was shown that white tea exerted the best protective effect on bone tissue and hyaline cartilage metabolism against synergic $\mathrm{Pb}$ and $\mathrm{Cd}$ action, while it seems that green tea had worse protective activity.

\section{References}

B r z ó s k a M.M. (2012). Low-level chronic exposure to cadmium enhances the risk of long bone fractures: A study on a female rat model of human lifetime exposure. J. Appl. Toxicol., 32: $34-44$.

B rzó s k a M.M., R o galsk a J., Ga lazyn-Si d or c zuk M., Jurczuk M., R os z c zenko A., Kulikowska-Karpińska E., Moniuszko-Jakoniuk J. (2007). Effect of zinc supplementation on bone metabolism in male rats chronically exposed to cadmium. Toxicology, 237 : 89-103.

Chen X., Zhu G., Jin T., L e i L., L i a n g Y. (2011). Bone mineral density is related with previous renal dysfunction caused by cadmium exposure. Environ. Toxicol. Pharmacol., 32: 46-53.

Cret a c c i Y., P a r s on s P.J. (2010). Localized accumulation of lead within and among bones from lead-dosed goats. Environ. Res., 110: 26-32.

Dermience M., Lognay G., Mathieu F., Goyens P. (2015). Effects of thirty elements on bone metabolism. J. Trace. Elem. Med. Biol., 32: 86-106.

Devine A., Hodgs on J.M., Dick I.M., Prince R.L. (2007). Tea drinking is associated with benefits on bone density in older women. Am. J. Clin. Nutr., 86: 1243-1247.

Dobrowolski P., Tomaszewska E., Kurlak P., Pierzynowski S.G. (2016). Dietary 2-oxoglutarate mitigates gastrectomy-evoked structural changes in cartilage of female rats. Exp. Biol. Med., 241: 14-24.

Duranova H., Martiniakova M., Imelka R., Gross kopf B., B obonova I., Toman R. (2014). Changes in compact bone microstructure of rats subchronically exposed to cadmium. Acta. Vet. Scand., 56: 64.

EFSA (2012 a). Lead dietary exposure in the European population. EFSA J., 10: 2831.

EFSA (2012 b). Cadmium dietary exposure in the European population. EFSA J., 10: 2551.

G a u r S., A g n i h o r t i R. (2014). Green tea: a novel functional food for the oral health of older adults. Geriatr. Gerontol. Int., 14: 238-250.

Green C.J., de Dauwe P., Bpyle T., Tabatabaei S.M., Fritschi L., Heyworth S. (2014). Tea, coffee, and milk consumption and colorectal cancer risk. J. Epidemiol., 24: 146-153.

G ü 1 ç in I., H u y u t Z., E 1 m a s t a ş M., A b o u 1 - E n e in H.Y. (2010). Radical scavenging and antioxidant activity of tannic acid. Arabian J. Chem., 3: 43-53.

Hila 1 Y., Enge lhardt U. (2007). Characterization of white tea - Comparison to green and black tea. J. Verbr. Lebensm., 2: 414-421. 
Hogervorst J., Plusquin M., Vangronsveld J., Nawrot T., Cuypers A., Van Heck e E., R o e ls H.A., C a r l e e r R., S t a e s s e n J.A. (2007). House dust as possible route of environmental exposure to cadmium and lead in the adult general population. Environ. Res., 103: 30-37.

J a m e s K.A., M el i k e r J.R. (2013). Environmental cadmium exposure and osteoporosis: a review. Int. J. Public Health., 58: 737-745.

Khal a f A.A., Mos elhy W.A., A b d e l- Ha med M.I. (2012). The protective effect of green tea extract on lead induced oxidative and DNA damage on rat brain. Neurotoxicol., 33: 280-289.

L a t touf R., Youn es R., Lut o mski D., N a a man N., God ea u G., S enni K., Changot a de S. (2015). Picrosirius red staining: a useful tool to appraise collagen networks in normal and pathological tissues. J. Histochem. Cytochem., 62: 751-758.

L i m H.S., L e e H.H., K i m T.H., L e e B.R. (2016). Relationship between heavy metal exposure and bone mineral density in Korean adult. J. Bone Metab., 23: 223-231.

M a e d a - Y a m a m o t o M. (2013). Human clinical studies of tea polyphenols in allergy or life stylerelated diseases. Curr. Pharm. Des., 19: 6148-6155.

Muszyński S., Kwiecień M., Tomaszewska E., Świetlicka I., Dobrowolski P., Ka s per ek K., J eż ew s k a - W it k ow s k a G. (2017). Effect of caponization on performance and quality characteristics of long bones in Polbar chickens. Poultry Sci., 96: 491-500.

Niedzwiecki A., Roomi M.W., Kalinovsky T., Rath M. (2016). Anticancer efficacy of polyphenols and their combinations. Nutrients, 8: E552.

Pem mer B., Roschger A., Wast 1 A., Hofstaet ter J.G., Wobrauschek P., Simon R., Thale r H.W., R os ch ger P., K l a u s h of er K., S tre li C. (2013). Spatial distribution of the trace elements zinc, strontium and lead in human bone tissue. Bone, 57: 184-193.

Qu in n T.M., M o r e 1 V. (2007). Microstructural modeling of collagen network mechanics and interactions with the proteoglycan gel in articular cartilage. Biomech. Model. Mechanobiol., 6: 73-82.

R e e ve s P.G., N i e l s e n F.H., F a h e y Jr. G.C. (1993). AIN-93 purified diets for laboratory rodents: final report of the American Institute of Nutrition ad hoc writing committee on the reformulation of the AIN-76A rodent diet. J. Nutr., 123: 1939-1951.

Sh e n C.L., Ye h J.K., C a o J.J., Chy u M.C., Wang J.S. (2011). Green tea and bone health: Evidence from laboratory studies. Pharmacol. Res., 64: 155-161.

S h e n C.L., C h y u M.C., Wa n g J.S. (2013). Tea and bone health: steps forward in translational nutrition. Am. J. Clin. Nutr., 98: 1694S-1699S.

Sheng J., Qu X., Zhang X., Zhai Z., Li H., Liu X., Li H., Liu G., Zhu Z., Hao Y., Q in A., D a i K. (2014). Coffee, tea, and the risk of hip fracture: a meta-analysis. Osteoporos. Int., 25: $141-150$.

S u vara S.K., La y to n C., B an croft J.D. (2013). Bancroft's theory and practice of histological techniques. Edinburgh, Churchill Livingstone, 7th ed., pp. 654.

Śliw a E. (2010). 2-Oxoglutaric acid administration diminishes fundectomy-induced osteopenia in pigs. J. Anim. Physiol. Anim. Nutr., 94: e86-e95.

Śliwa E., Kowalik S., Tatara M.R., Krupski W., Majcher P., Euszczewska- S i e rakow s k a I., P i e rzy now sk i S.G., S t u d ziń s ki T. (2005). Effect of alpha-ketoglutarate $(\mathrm{AKG})$ given to pregnant sows on development of humerus and femur in newborns. Bull. Vet. Instit. Pulawy., 49: 117-120.

Śliwa E., Tat ara M.R., Nowakowski H., Pi erzynowski S.G., Studziński T. (2006). Effect of maternal dexamethasone and alpha-ketoglutarate administration on skeletal development during the last three weeks of prenatal life in pigs. J. Matern. Fetal Neonatal Med., 19: 489-493.

Tomaszewska E., Dobrowolski P., Siwicki A. (2012 a). Maternal treatment with dexamethasone at minimal therapeutic doses inhibits neonatal bone development in a gender-dependent manner. Livest. Sci., 146: 175-182.

To m a s z ew s ka E., D obrow olski P., Wy dry ch J. (2012 b). Postnatal administration of 2-oxoglutaric acid improves articular and growth plate cartilages and bone tissue morphology in pigs prenatally treated with dexamethasone. J. Physiol. Pharmacol., 63: 547-554.

To mas zew ska E., D o brow olsk i P., Puzi o I. (2013). Morphological changes of the cartilage and bone in newborn piglets evoked by experimentally induced glucocorticoid excess during pregnancy. J. Anim. Physiol. Anim. Nutr., 97: 785-796.

Tomaszewska E., Winiarska-Mieczan A., Dobrowolski P. (2015 a). The lack of pro- 
tective effects of tea supplementation on liver and jejunal epithelium in adult rats exposed to cadmium and lead. Environ. Toxicol. Pharmacol., 40: 708-714.

Tomaszewska E., Winiarska-Mieczan A., Dobrowolski P. (2015 b). Hematological and serum biochemical parameters of blood in adolescent rats and histomorphological changes in the jejunal epithelium and liver after chronic exposure to cadmium and lead in the case of supplementation with green tea vs black, red or white tea. Exp. Toxicol. Pathol., 67: 331-339.

Tomaszewska E., Dobrowolski P., Winiarska-Mieczan A., Kwiecień M., Tomczyk A., Muszyński S., Radzki R. (2016). Alteration in bone geometric and mechanical properties, histomorphometrical parameters of trabecular bone, articular cartilage and growth plate in adolescent rats after chronic co-exposure to cadmium and lead in the case of supplementation with green, black, red and white tea. Environ. Toxicol. Pharmacol., 46: 36-44.

Tomaszewska E., Dobrowolski P., Winiarska-Mieczan A., Kwi ecień M., Tomczyk A., Muszyński S. (2017 a). The effect of tannic acid on the bone tissue of adult male Wistar rats exposed to cadmium and lead. Exp. Toxicol. Pathol., 69: 131-141.

Tomaszewska E., Kwiecień M., Muszyński S., Dobrowolski P., Kasperek K., B licharski T., Jeżewska-Witkowska G., Grela E.R. (2017 b). Long-bone properties and development are affected by caponisation and breed in Polish fowls. Brit. Poultry Sci., 58: 312-318.

WHO (1992). Environmental health criteria 134: Cadmium. Geneva, World Health Organization, pp. 280.

Z h a $\mathrm{g}$ Z.F., Yan g J.L., J i a $\mathrm{g}$ H.C., L a i Z., W u Z., L i u Z.X. (2017). Updated association of tea consumption and bone mineral density: A meta-analysis. Medicine, 96: e6437.

Received: 26 I 2018

Accepted: 17 V 2018 